Check for updates

Cite this: Chem. Sci., 2020, 11, 409

- All publication charges for this article have been paid for by the Royal Society of Chemistry

Received 30th September 2019

Accepted 16th November 2019

DOI: $10.1039 / c 9 s c 04906 a$

rsc.li/chemical-science

\section{Separation of halogenated benzenes enabled by investigation of halogen $-\pi$ interactions with carbon materials $\uparrow$}

\author{
Eisuke Kanao, ${ }^{a}$ Takuya Morinaga, ${ }^{a}$ Takuya Kubo, (D) *a Toyohiro Naito, ${ }^{a}$ \\ Takatoshi Matsumoto, iD b Tomoharu Sano, ${ }^{\mathrm{C}}$ Hideshi Maki, iD de Mingdi Yan ${ }^{\mathrm{f}}$ \\ and Koji Otsuka iD a
}

\begin{abstract}
The halogen $-\pi(X-\pi)$ interaction is an intermolecular interaction between the electron-poor region of bonded halogen atoms and aromatic rings. We report an experimental evaluation of the halogen $-\pi(X-$ $\pi$ ) interaction using liquid chromatography with carbon-material coated columns providing strong $\pi$ interactions in the normal phase mode. $\mathrm{A}_{70}$-fullerene (C70)-coated column showed higher retentions for halogenated benzenes as the number of halogen substitutions increased as a result of $X-\pi$ interactions. In addition, the strength of the $\mathrm{X}-\pi$ interaction increased in the order of $\mathrm{F}<\mathrm{Cl}<\mathrm{Br}<\mathrm{I}$. Changes to the UV absorption of C70 and the brominated benzenes suggested that the intermolecular interaction changed from the $\pi-\pi$ interaction to $X-\pi$ interaction as the number of bromo substitutions increased. Computer simulations also showed that the difference in dipole moments among structural isomers affected the strength of the $\pi-\pi$ interaction. Furthermore, we concluded from small peak shifts in ${ }^{1} \mathrm{H}$ NMR and from computer simulations that the orbital interaction contributes to the $X-\pi$ interactions. Finally, we succeeded in the one-pot separation of all isomers of brominated benzenes using the $\mathrm{C} 70$-coated column by optimizing the mobile phase conditions.
\end{abstract}

\section{Introduction}

Advances in computational chemistry have enabled investigations of large charge deflections in halogen atoms. The low electron density region along the $\sigma$ bonding axis of bonded halogen atoms, known as the " $\sigma$ hole," interacts propitiously with electron donor species. ${ }^{\mathbf{1 - 5}}$ This halogen bonding interaction has attracted interest in many fields, such as molecular biology ${ }^{6,7}$ and crystal engineering, ${ }^{8,9}$ due to its high molecular selectivity and linear directionality. ${ }^{\mathbf{1 0 - 1 4}}$ In particular, halogen bonding has been positively applied to develop new functional

${ }^{a}$ Graduate School of Engineering, Kyoto University, Katsura, Nishikyo-ku, Kyoto 615-8510, Japan. E-mail: kubo.takuya.6c@kyoto-u.ac.jp; Fax: +81-75-383-2450; Tel: +81-75-383-2448

${ }^{b}$ Institute of Multidisciplinary Research for Advanced Materials, Tohoku University, 21-1, Katahira, Aoba-ku, Sendai 980-8577, Japan

${ }^{c}$ Center for Environmental Measurement and Analysis, National Institute for Environmental Studies, Onogawa 16-2, Tsukuba, Ibaraki 305-8506, Japan

${ }^{d}$ Center for Environmental Management, Kobe University, 1-1 Rokkodai-cho, Nada-ku, Kobe 657-8501, Japan

${ }^{e}$ Department of Chemical Science and Engineering, Graduate School of Engineering, Kobe University, 1-1 Rokkodai-cho, Nada-ku, Kobe 657-8501, Japan

${ }^{f}$ Department of Chemistry, University of Massachusetts Lowell, One University Ave., Lowell, MA 01854, USA

$\uparrow$ Electronic supplementary information (ESI) available. See DOI: 10.1039/c9sc04906a materials ${ }^{\mathbf{1 5 - 1 8}}$ since Nguyen et al. first synthesized liquid crystals designed with halogen bonds in 2004. ${ }^{19}$ An example is the Rotaxane structure with iodo groups synthesized by Barendt et al. that selectively recognized nitrogen anions via halogen bonding, producing drastic color changes. ${ }^{20}$ Another example is the iodoperfluoroarene-substituted polystyrene synthesized by Vanderkooy et al. that controlled the self-assembly of nanostructures of polymer aggregates by halogen bonding. ${ }^{21}$ According to recent reports, halogen bonding greatly contributes to molecular recognition in vivo and has thus been applied in designing drugs, ${ }^{22-24}$ such as aldose reductase inhibitors ${ }^{25}$ and HIV-1 inhibitors. ${ }^{26}$ Therefore, fully understanding the characteristics of halogen bonding may drastically facilitate the advancement of materials chemistry.

Notably, halogen bonding between halogen groups and $\pi$ electrons of aromatic rings or unsaturated bonds acting as electron donors, i.e., "halogen $-\pi(\mathrm{X}-\pi)$ interactions," plays important roles in biological systems. ${ }^{27-30}$ Voth et al. reported the first $\mathrm{X}-\pi$ interactions in biological systems. ${ }^{31}$ They found that the interactions between the aromatic rings of phenyl residues inhibited the protein kinases CDK2 and CK2. Data on $\mathrm{X}-\pi$ interactions in biological systems rapidly grew following Voth's report, and the $\mathrm{X}-\pi$ interaction now occupies about $30 \%$ of the current reports on halogen bonding in protein-ligand complexation. ${ }^{32}$ The importance of $\mathrm{X}-\pi$ interactions is now recognized, and many properties (magnitude directionality and 
origin of the $\mathrm{X}-\pi$ interaction) have been clarified with high level computational methods based on theoretical chemistry. ${ }^{33,34}$

Despite the progress, additional experimental data on $\mathrm{X}-\pi$ interactions are necessary because the halogen bond is in physical competition with many other stronger noncovalent interactions, including the hydrophobic interaction, hydrogen bond, and electrostatic interaction..$^{35-37}$ As a few reports, Nazaré et al. indicated the experimental approach to reveal the strength of halogen- $\pi$ interaction using bicyclic $N$-arylimide based molecular torsion balances system. ${ }^{38}$ Although the study showed the presence of halogen- $\pi$ interaction in intramolecular system, few studies reported regarding halogen $-\pi$ interaction for intermolecular system. On the other hand, high performance liquid chromatography (HPLC) is a powerful separation technique that utilizes the difference in partition coefficients between the solutes of the mobile and stationary phases, a factor that sensitively reflects the strength of the noncovalent interaction..$^{39,40}$ In our previous studies, we developed novel separation media immobilized with carbon materials. ${ }^{41-43}$ These media exhibited strong $\pi$ interactions because of their many $\pi$ electrons. Characteristics of weak interactions from aromatic rings were clarified by evaluating their retention behaviors with HPLC measurements. This included the $\pi-\pi$ interaction based on the spherical recognition of $\mathrm{C}_{60^{-}}$or $\mathrm{C}_{70^{-}}$ fullerenes $(\mathrm{C60} / \mathrm{C} 70)$, the difference in intensity of the $\mathrm{CH}$ or $\mathrm{CD}-\pi$ interaction, and the strong $\mathrm{CH}-\pi$ interaction between corannulene and planar polycyclic aromatic hydrocarbons.

We also uncovered the possibility for the separation of halogenated aromatic compounds resulting from the efficient halogen $-\pi$ interactions in HPLC. ${ }^{44}$ The aromatic halogens, such as polychlorinated biphenyls (PCBs) ${ }^{45,46}$ and polybrominated diphenyl ethers (PBDEs), ${ }^{47-49}$ are widely known to be highly toxic; therefore, we need monitor the concentration of these pollutions in our environment. Usually, these aromatic halogens are analyzed by gas-chromatography or reverse-phase liquid chromatography, which involve complicated preparation processes. Even with these existing methods, the separation of the full variety of isomers by the direct analysis of the sample in oil or after extraction with non-polar solvents is difficult because only factors driving the separation are the differences in vaporization or hydrophobicity between the compounds. In addition, the halogen $-\pi$ interaction has never been utilized for the separation of these aromatic halogens. Thus, we hypothesized that the effective halogen $-\pi$ interaction would enable the efficient separation of the isomers of aromatic halogens and that the one-pot separation system will contribute to the straightforward monitoring of environmental pollutions like PCBs and PBDEs.

In the present study, we experimentally evaluated the strength of the $\mathrm{X}-\pi$ interaction between carbon materials and a variety of halogenated benzenes using normal phase liquid chromatography (NPLC). The hydrophobic interaction was completely suppressed in this technique, and thus the $\pi$ interactions could be simply examined. Furthermore, we accurately evaluated the $\pi$ interactions between halogenated benzenes and C70 using ultraviolet-visible (UV-Vis) and ${ }^{1} \mathrm{H}$ NMR spectroscopy. Finally, we demonstrate the one-pot separation of the entirety of the brominated benzenes (11 analogues) by optimizing the mobile phase conditions to control the $\mathrm{X}-\pi$ interactions.

\section{Results and discussion}

\section{Method}

The detailed experimental procedures including chemicals, instruments, the synthesis of the molecules, the preparation of the monoliths, and computational methods are summarized in the ESI. $\dagger$

The silica-monolithic capillary was treated with $1.0 \mathrm{M}$ aqueous sodium hydroxide at $40{ }^{\circ} \mathrm{C}$ for $3 \mathrm{~h}$. After washing with water and methanol, 3-aminopropyltrimethoxysilane (APTMS) in methanol $(10 \%, \mathrm{v} / \mathrm{v})$ was passed through the silicamonolithic capillary for $24 \mathrm{~h}$ and washed with methanol. C60/C70-4-azido-2,3,5,6-tetrafluorophenyl succinate (PFPANHS) in toluene $\left(3.0 \mathrm{mg} \mathrm{mL}^{-1}\right)$ was charged into the $\mathrm{NH}_{2}$ monolith for $24 \mathrm{~h}$ at room temperature and washed with toluene and methanol (Scheme S2 $\dagger$ ). A column that was modified with only the linkers or PFPA column (Scheme S3†) was also prepared and used as a control. $\mathrm{NH}_{2}$ groups on the silica-monolith surface and C70-PFPA-NHS were reacted under the conditions in Table $\mathrm{S} 2 . \dagger$ For comparing column performances, we evaluated retention factors and separation factors of phenanthrene and corannulene, which showed specific intermolecular interaction with $\mathrm{C} 70$ due to its spherical recognition. Fig. S2a $\uparrow$ shows the retention factors of phenanthrene and corannulene obtained and the separation factor for each column. The chromatograms of the phenanthrene and corannulene mixture obtained with column 1 and column 4 are shown in Fig. S2b. $\uparrow$ Column 4 showed the largest retention factor and separation factor. This result clearly suggested that the separation performance of the column was successfully improved by increasing the reaction time and concentration of C70-PFPA-NHS in the reaction solution. We then used column 4 to evaluate the separation performance of the structural isomers of halogenated benzenes (column 1 is defined as Type1 and column 4 is defined as Type-2).

\section{Retention of halogenated benzenes on carbon-material coated columns in NPLC}

We evaluated the retention of halogenated benzenes on four different carbon-material ( $\pi$ NAP, 5PYE, C60, and C70) coated columns (Fig. 1). Here, when we employed octadecylsilyl bonded silica (C18) column, which is typically used in HPLC based on hydrophobic interaction, all the halogenated benzenes were not retained at all. Herefrom, the hydrophobic interaction was not worked in our LC system and we could ignore the effect of hydrophobicity in later discussions.

Fig. 1a shows the retention factors $k\left(k=\left(t_{\mathrm{R}}-t_{0}\right) / t_{0}\right.$ where $t_{\mathrm{R}}$ is the retention time of a solute and $t_{0}$ is the elution time of nonretained solute) of brominated benzenes on each carbonmaterial coated column against the number of bromo substitutions in the solutes. All the carbon-material coated columns showed higher retentions as the number of bromo substitutions increased. On contrary, fluorinated benzenes were not retained 
<smiles>CC(C)(C)CC1CCCC1</smiles>

TNAP

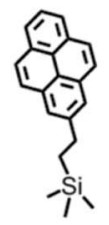

5PYE

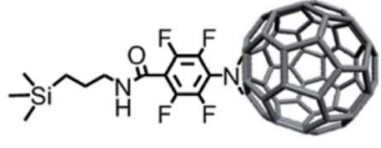

C60-coated column

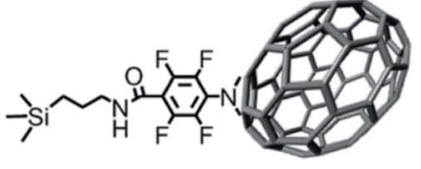

C70-coated column (a)

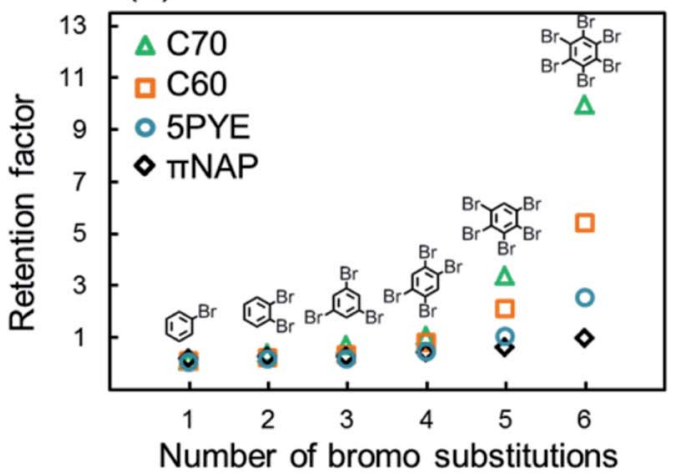

(b)

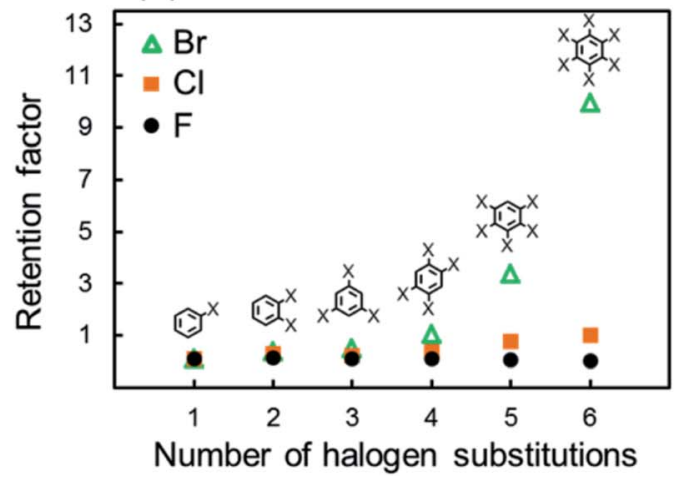

Fig. 1 Structure of the stationary phases and retention behaviors of halogenated benzenes with carbon-material coated columns in NPLC. (a) Retention factors of brominated benzenes with each column and the number of brominated substitutions. (b) Retention factors of each halogenated benzene with the $\mathrm{C} 70$-coated column and the number of halogen substitutions. Conditions: column, C60-coated (28.8 $\mathrm{cm} \times 100$ $\mu \mathrm{m}$ i.d.), C70-coated (Type-1, $25.5 \mathrm{~cm} \times 100 \mu \mathrm{m}$ i.d.), 5 PYE $\left(150 \mathrm{~mm} \times 4.6 \mathrm{~mm}\right.$ i.d.), $\pi \mathrm{NAP}\left(50 \mathrm{~mm} \times 2.0 \mathrm{~mm}\right.$ i.d.); flow rate; $2.0 \mu \mathrm{L} \mathrm{min}{ }^{-1}(\mathrm{C} 70$,

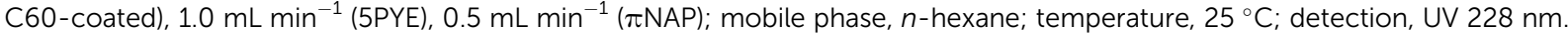

on the C70 column at all. As shown in a few previous studies, $\sigma$ hole was not identified because of small atom of fluorine, so that $\mathrm{X}-\pi$ interaction was not occurred in fluorinated molecules. $^{50,51}$ Briefly, the presence of halogen- $\pi$ interaction was confirmed except fluorinated molecules. ${ }^{2,52}$

The results indicated that the $\mathrm{X}-\pi$ interactions existed between the aromatic rings in the stationary phases and the bromo substitutions of the solutes. The C70-coated column showed significantly higher retentions for brominated benzenes. PFPA, the linker of the C70-coated column, did not provide such high retention, as shown in Table S1; $\uparrow$ therefore, we concluded that the $\mathrm{C} 70$ moiety was responsible for the high retentions of the brominated benzenes.

Furthermore, in order to evaluate the impact of the halogen species in the solutes on retention behaviors, the retention factors of benzenes with various halogens on the C70-coated column were measured and plotted in Fig. $1 \mathrm{~b}$ against the number of halogen substitutions in the solutes. The C70-coated column did not retain any fluorinated benzenes. This result suggested that fluorine substitutions were not capable of meaningful $\mathrm{X}-\pi$ interactions. Alternatively, the C70-coated column retained chlorinated and brominated benzenes and showed higher retentions as the number of halogen substitutions increased. However, the absolute retentions and the retention differences across the number of halogen substitutions of the chlorinated benzenes were much less than those of the brominated benzenes. Additionally, the iodinated benzenes were strongly retained on C70 column in the same condition, especially penta- and hexa-iodinated benzenes were not eluted, therefore, it is so hard to compare in this figure. The detailed discussions regarding stronger $\mathrm{X}-\pi$ interaction for iodinated benzenes are described later.

The chromatograms of chlorinated benzenes (Fig. 2a) and brominated benzenes (Fig. 2b) also clearly showed poorer resolution for the chlorinated benzenes. These results indicated that the $\mathrm{X}-\pi$ interactions of chlorine substitutions were weaker than those of their bromine counterparts.

Here, we hypothesized that the $\mathrm{X}-\pi$ interaction becomes stronger as the size of the substituting halogen increases. A few reports in the literature support our hypothesis; briefly, the size of the $\sigma$ hole increases with the size of the halogen. ${ }^{53-55}$ In order to confirm our hypothesis, we evaluated the retention behaviors of the hexa-halogenated benzenes $\left(\mathrm{C}_{6} \mathrm{~F}_{6}, \mathrm{C}_{6} \mathrm{Cl}_{6}, \mathrm{C}_{6} \mathrm{Br}_{6}, \mathrm{C}_{6} \mathrm{I}_{6}\right)$ in NPLC with the C70-coated column. Fig. 2c shows the chromatograms of the mixed sample of hexa-halogenated benzenes. In consideration of the solubility of $\mathrm{C}_{6} \mathrm{I}_{6}$, tetrahydrofuran (THF) was added to the mobile phase in this separation. As shown in Fig. 2c, the elution order in the C70-coated column was $\mathrm{C}_{6} \mathrm{~F}_{6}<$ $\mathrm{C}_{6} \mathrm{Cl}_{6}<\mathrm{C}_{6} \mathrm{Br}_{6}<\mathrm{C}_{6} \mathrm{I}_{6}$. As expected, larger halogen atoms enabled higher retentions; the differences in the $\mathrm{X}-\pi$ interactions should account for this trend.

\section{Evaluation of $\pi-\pi$ interactions between brominated benzenes and C70 by UV-Vis spectroscopy}

In the interaction between halogenated benzenes and aromatic carbon-materials, typical $\pi-\pi$ interactions could also contribute 
(a)

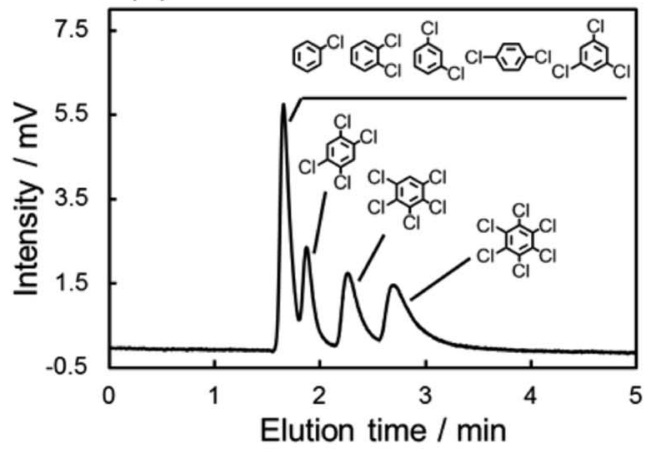

(b)

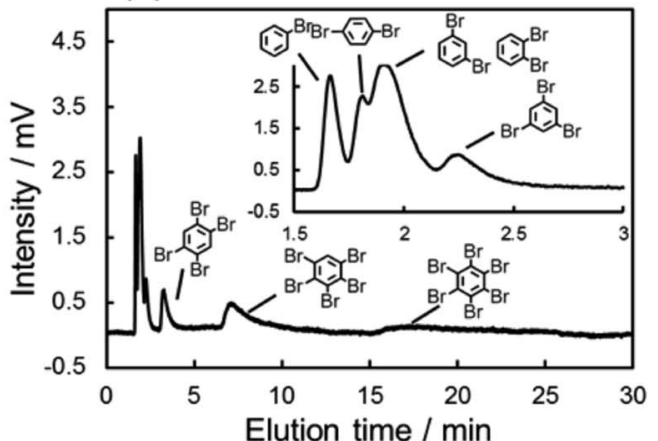

(c)

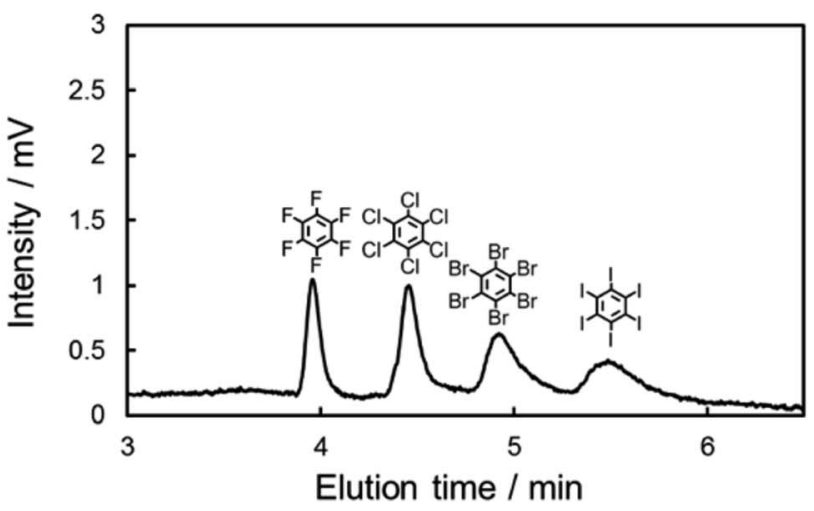

Fig. 2 Chromatograms of the mixed sample of (a) chlorinated benzenes, (b) brominated benzenes, and (c) the mixture of hexa-halogenated benzenes with the C70-coated column. Conditions: (a) and (b) column, C70-coated (Type-1, $25.5 \mathrm{~cm} \times 100 \mu \mathrm{m}$ i.d.); flow rate; $2.0 \mu \mathrm{L} \mathrm{min}{ }^{-1}$; mobile phase, $n$-hexane; temperature, $25^{\circ} \mathrm{C}$; detection, UV $228 \mathrm{~nm}$; (c) column, C70-coated (Type-1, $75.0 \mathrm{~cm} \times 100 \mu \mathrm{m}$ i.d.); flow rate; 2.0 $\mu \mathrm{L} \min ^{-1}$; mobile phase, $n$-hexane/THF $=7 / 3$; temperature, $25^{\circ} \mathrm{C}$; detection, UV $228 \mathrm{~nm}$.

in addition to the $\mathrm{X}-\pi$ interactions. In order to evaluate the contributions of $\pi-\pi$ interactions to the retention of brominated benzenes, we focused on the differences in UV-Vis absorption spectra of halogenated benzenes with/without C70. Several previous studies reported that the $\pi-\pi$ interaction attenuated a certain absorbance region in UV-Vis. ${ }^{41,56}$ The absorption spectra of $o$-dibromobenzene $(10 \mu \mathrm{M})$ with/without C70 $(10 \mu \mathrm{M})$ in $n$-hexane are shown in Fig. 3a. Interestingly, the spectrum dramatically changed when C70 was added to the solution. Similar spectral alterations were observed for other brominated benzenes (Fig. S1†). These results suggested that the $\pi-\pi$ interaction also contributes to the intermolecular interaction between brominated benzenes and C70. Alternatively, the absorption spectra with larger numbers of bromine substitutions $(n>3)$, especially hexabromobenzene, were almost unchanged. We assumed that the extent of (a)

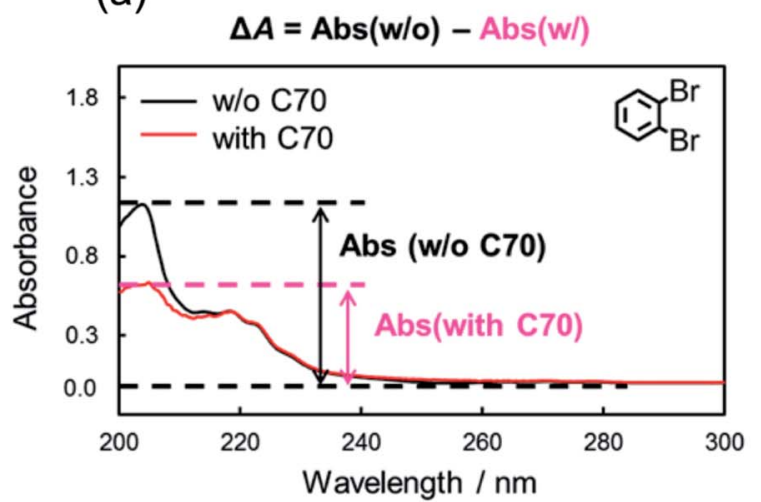

(b)

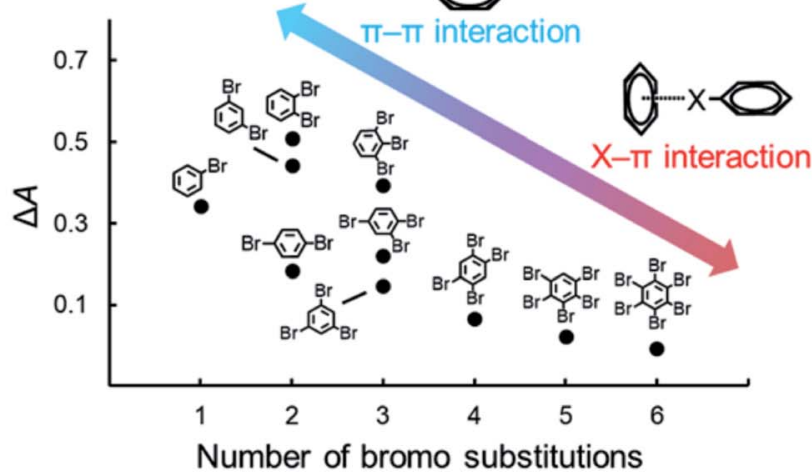

Fig. 3 Absorption spectra of o-dibromobenzene in $n$-hexane with/without C70 (a) and difference of absorbance in maximum wavelength (205 $\mathrm{nm}$ ) of brominated benzenes with/without C70 (b). 
(a)

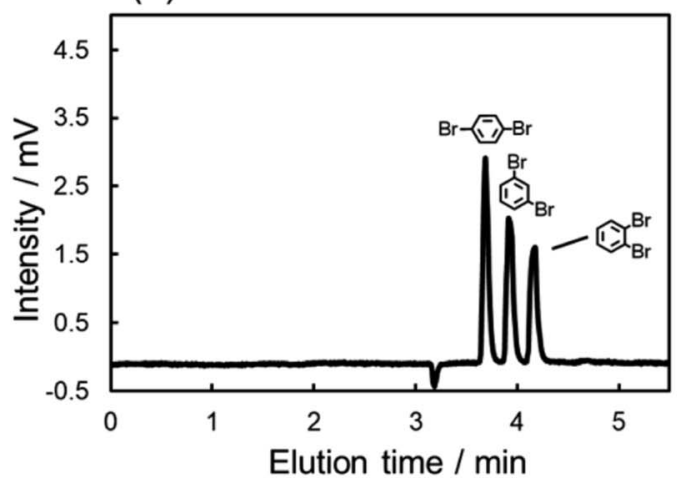

(b)

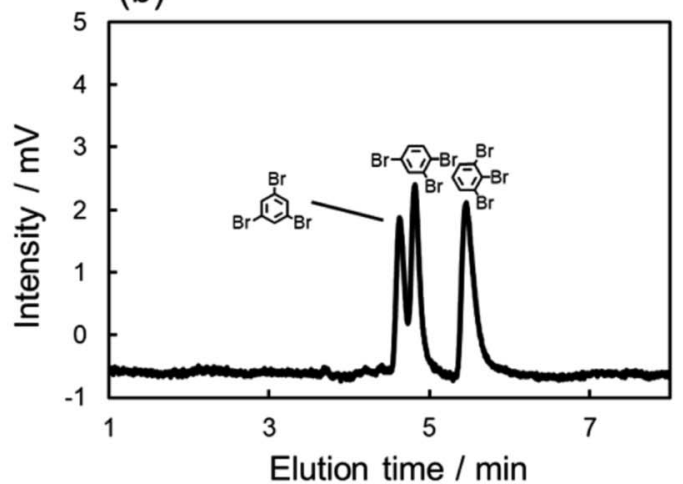

Fig. 4 Chromatograms of the mixture of (a) di- or (b) tri-brominated benzenes with the C70-coated column (the C70-coated, Type-2). Conditions: column, C70-coated (Type-2, $75.0 \mathrm{~cm} \times 100 \mu \mathrm{m}$ i.d.); flow rate; $2.0 \mu \mathrm{L} \mathrm{min}{ }^{-1}$; mobile phase, $n$-hexane; temperature, $25{ }^{\circ} \mathrm{C}$; detection, UV $228 \mathrm{~nm}$.

contributions of the $\pi-\pi$ interactions to the intermolecular interaction with $\mathrm{C} 70$ was different for these solutes. To evaluate the difference in detail, we calculated the difference in absorbance at the maximum wavelength (around $205 \mathrm{~nm}$, typical specific absorption for the $\pi-\pi^{*}$ transition $^{57}$ ) between columns with and without C70 $(\Delta A)$. Fig. 3b summarizes $\Delta A$ for each solute against the number of bromine substitutions. Based on this figure, we supposed that fewer bromine substitutions allowed stronger $\pi-\pi$ interactions while higher bromine substitutions were mainly dominated by the $\mathrm{X}-\pi$ interaction. Briefly, the degree of the contribution by the $\pi-\pi$ interaction between brominated benzenes and $\mathrm{C} 70$ followed a trend opposite to that of retention strength of brominated benzenes on the C70-coated column (Fig. 1). In higher bromine substitutions, the relatively stronger $\mathrm{X}-\pi$ interaction may dominantly contribute to the higher retentions on the C70-coated column. From these results, we conclude that both the $\mathrm{X}-\pi$ interaction and the $\pi-\pi$ interaction are competitively involved in the

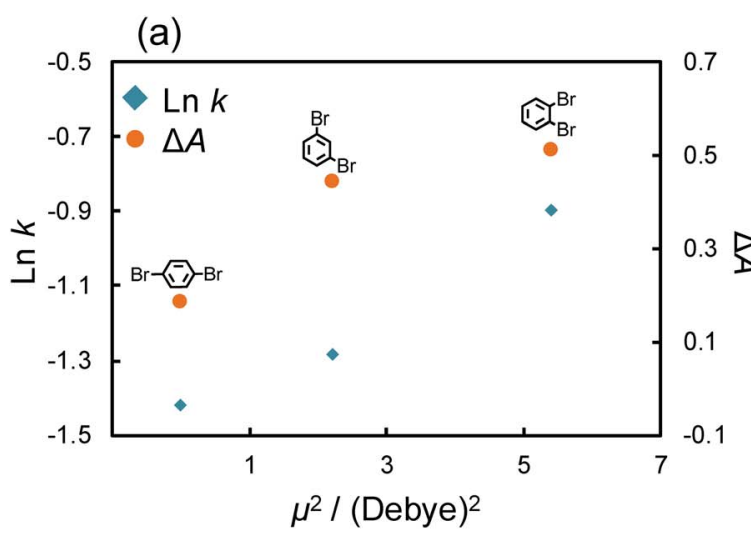

(c)

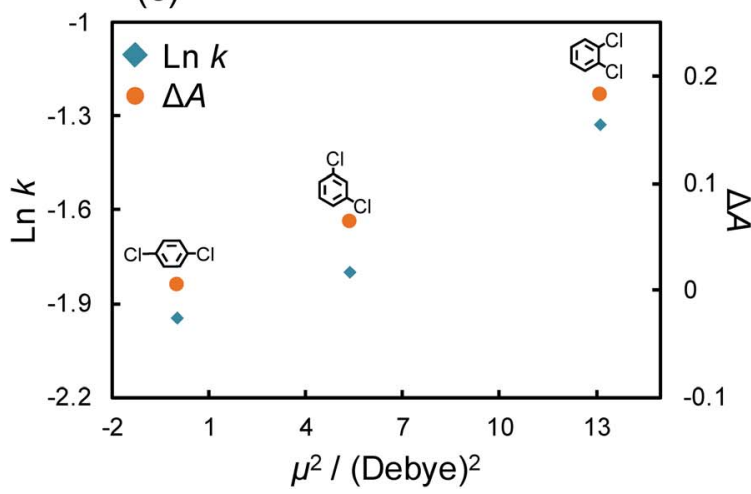

(b)

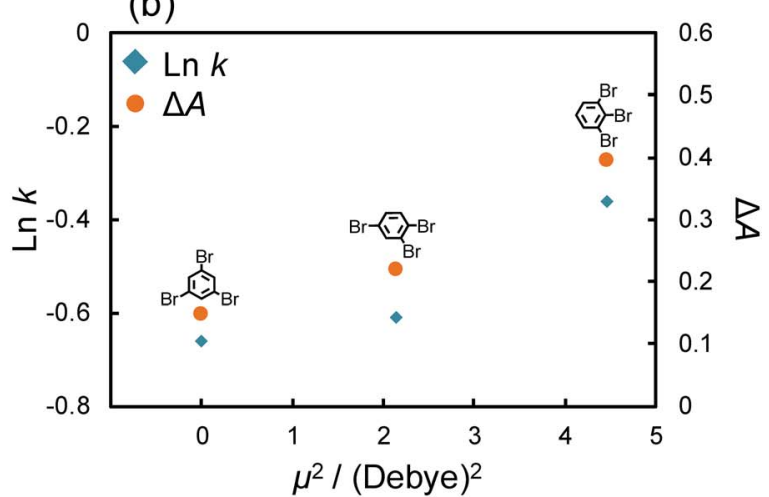

(d)

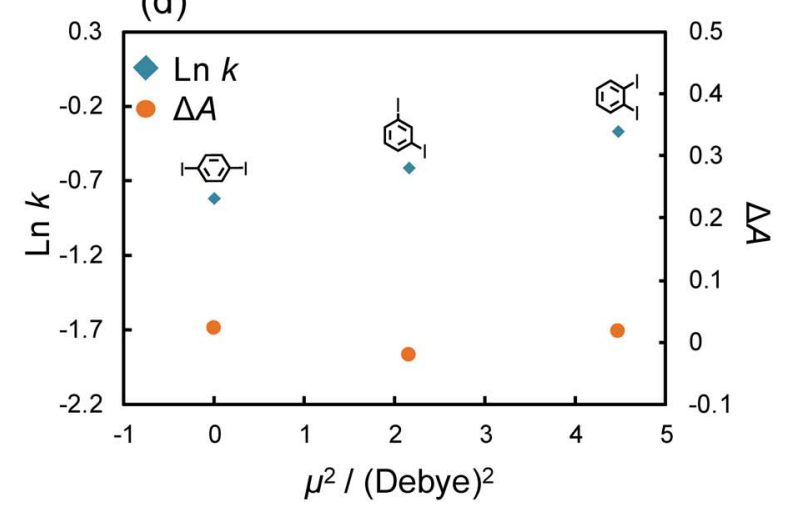

Fig. 5 Logarithm of the retention factor or $\Delta A$ of (a) di- or (b) tri-brominated benzenes and (c) di-chlorinated or (d) di-iodinated benzenes with the C70-coated column against square of dipole moment in each solute. Conditions: column, C70-coated (Type-2, $75.0 \mathrm{~cm} \times 100 \mu \mathrm{m}$ i.d.); flow rate; $2.0 \mu \mathrm{L} \mathrm{min}^{-1}$; mobile phase, $n$-hexane; temperature, $25^{\circ} \mathrm{C}$; detection, UV $228 \mathrm{~nm}$. 
intermolecular interaction between halogenated benzenes and C70.

\section{Separation of the structural isomers enabled by differences in dipole moments}

As described above, large differences of $\Delta A$ were also observed among the isomers of dibromo and tribromobenzenes. These absorbance changes were expected to indicate the strength of the $\pi-\pi$ interaction between each structural isomer and C70. Thus, we anticipated that the C70-coated column could efficiently separate the isomers by optimizing the LC conditions to exploit the differences in the strength of the interactions. To achieve such separations, we improved the procedure of preparing a C70-coated column; in brief, we attempted to increase the concentration of C70-PFPA-NHS in the reaction solution to improve the immobilization amount of C70 (see ESI $\dagger$ ). Then, we obtained another C70-coated column (Type-2), in which a high density of C70 was immobilized.

We evaluated the separation behavior of the mixture of dibromobenzenes or tribromobenzenes with the Type-2 column. Fig. 4 shows chromatograms for the mixture of isomers. As we expected, the separation of these structural isomers was successfully achieved. Furthermore, the elution orders on the column, i.e., o-dibromobenzene $>m$-dibromobenzene $>p$-dibromobenzene, 1,2,3-tribromobenzene $>1,2,4$ tribromobenzene $>1,3,5$-tribromobenzene, followed the trend of $\pi-\pi$ interaction contributions (Fig. 3b). Consequently, we anticipated that the retention differences were a result of the differences in the strength of the $\pi-\pi$ interaction.

To investigate the differences in strength of the $\pi-\pi$ interactions, we considered the dipole moments of these structural isomers. The strength of the $\pi$ interaction is considered to be determined by the induced dipole-dipole interaction or the induced dipole-induced dipole interaction. ${ }^{33,58-62}$ The potential energy of the induced dipole-dipole interaction is given as follows:

$$
G_{\text {induced dipole-dipole }}=-\mu^{2} \alpha_{1} /\left(4 \pi \varepsilon_{0} \varepsilon_{\mathrm{r}}\right)^{2} r^{6}
$$

where, $\mu$ is the dipole moment of the polar molecule, $\alpha$ is the polarizability of the other interacting molecule, $\varepsilon_{0}$ is the permittivity of vacuum, $\varepsilon_{\mathrm{r}}$ is the relative permittivity of the solvent, and $r$ is the distance between the molecules. In addition, the potential energy of the induced dipole-induced dipole interaction is given as follows:

$$
G_{\text {induced dipole-induced dipole }}=-A \alpha_{1} \alpha_{2} /\left(4 \pi \varepsilon_{0} \varepsilon_{\mathrm{r}}\right)^{2} r^{6}
$$

where, the polarizabilities of each interacting molecule are involved. Since halogen atoms have strong withdrawing properties and thus halogenated benzenes have large dipole moments across the aromatic ring, we could predict that the $\pi-$ $\pi$ interaction was a result of the induced dipole-dipole interaction and that higher dipole moments allowed stronger $\pi-\pi$ interactions in our experiments. We then carried out computer simulations to calculate the dipole moments of the solutes (Table S3†); Fig. 5a and b shows the retention factors and $\Delta A$ against $\mu^{2}$. The logarithm of the retention factor was plotted in order to correspond to the potential energy based on the equation of distribution equilibrium. ${ }^{63}$ Both di- and tribrominated structural isomers showed stronger retentions and larger contributions of the $\pi-\pi$ interaction as the dipole moment strength increased. The theoretical considerations also supported the notion that $\mathrm{di}$ - and tri-brominated benzenes express different strengths of $\pi-\pi$ interactions based on the magnitude of their dipole moments.

In a fashion similar to the above experiments, we evaluated the effect of the $\pi-\pi$ interaction for chlorine and iodine substitutions. Fig. S3† shows the chromatograms of dichlorinated and di-iodinated benzenes. The separation of these structural isomers was confirmed even though the separation efficiency was poorer than that of the bromine substitutions. Here, we again evaluated the retention factor and $\Delta A$ of each solute and calculated their dipole moments (Table $\mathrm{S} 3 \dagger$ ). The absorption spectra of structural isomers of dichloro and di-iodo benzenes $(10 \mu \mathrm{M})$ with/without C70 $(10 \mu \mathrm{M})$ in $n$-hexane are shown in Fig. S4. $\dagger$ Fig. $5 \mathrm{c}$ and $\mathrm{d}$ show the retention factors and the $\Delta A$ of di-chlorinated and iodinated benzenes against $\mu^{2}$. Chlorinated benzenes showed larger

(a)

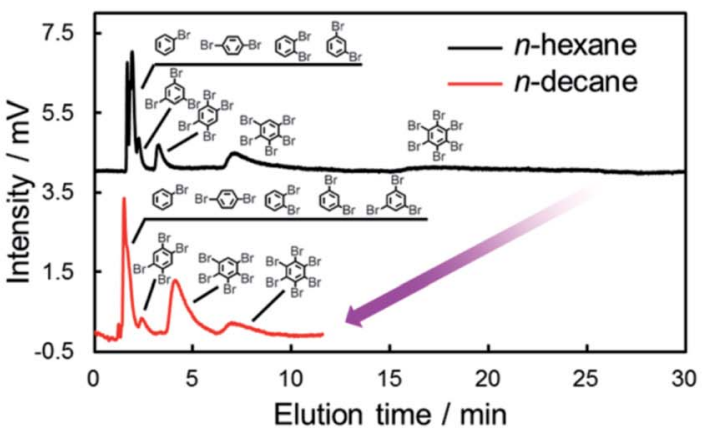

(b)

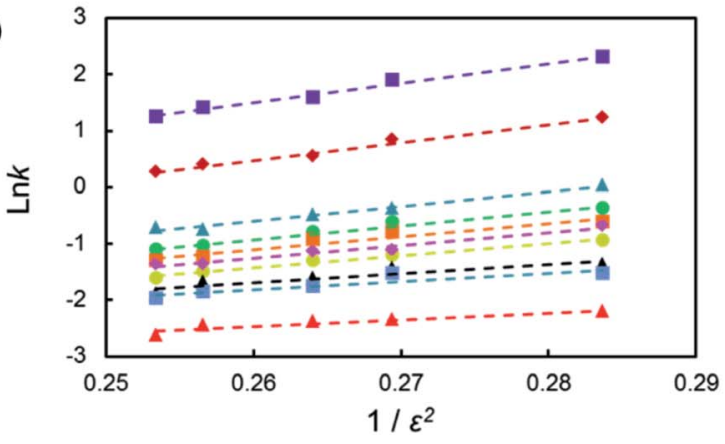
A bromobenzene
- o-dibromobenzene
A m-dibromobenzene
a $p$-dibromobenzene
1,3,4-tribromobenzene
1,3,5-tribromobenzene
A 1,2,4,5-tetrabromobenzene
1,2,3-tribromobenzene
$\checkmark$ pentabromobenzene
- hexabromobenzene

Fig. 6 Chromatograms of the mixture of brominated benzenes with the C70-coated column (a) and In $k$ against $1 / \varepsilon^{2}$ in each NA mobile phase (b). Conditions: column, C70-coated (Type-1, $25.5 \mathrm{~cm} \times 100$

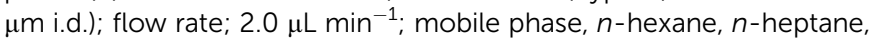
$n$-octane, $n$-nonane, $n$-decane; temperature, $25^{\circ} \mathrm{C}$; detection, UV $228 \mathrm{~nm}$. 
retention factors and $\Delta A$ as their dipole moments increased in comparison to brominated benzenes (Fig. 5c). The results indicated that structural isomers of chlorinated benzenes showed the differences in strength of $\pi-\pi$ interactions with the magnitudes of their dipole moments as we expected. Surprisingly, di-iodinated benzenes showed little change in $\Delta A$, and no correlation between $\Delta A$ and their dipole moment was observed. We considered that the differences in the retentions of di-iodo benzenes were not a result of the $\pi-\pi$ interaction. As mentioned above, the $\sigma$ hole of iodine groups is the largest and shows the strongest halogen- $\pi$ interactions amongst the halogen groups. Additionally, Präsang et al. reported that stronger $\mathrm{X}-\pi$ interaction is occurred by substitution of the electron withdrawing functional groups to next carbon atom on the aromatic rings. ${ }^{64}$ In our case, the $\mathrm{X}-\pi$ interaction strength could be shown in the order of $o$ - $>m$ - $>p$-di-iode benzenes. This is because iodine also has an electron withdrawing effect and the strength of the withdrawing effect follows the order of $o$ - > $m$ - > p-di-iode benzenes.

\section{Effect of dielectric constants in mobile phases}

As shown in eqn (1) and (2), the induced-dipole interaction is strongly influenced by the dielectric constant $(\varepsilon)$ of the solvents. Fig. 6a shows the chromatograms of the mixtures of halogenated benzenes in $n$-hexane or $n$-octane mobile phases with the C70-coated column. As expected, the retentions for halogenated benzenes with the C70-coated column were drastically lower with $n$-octane than with $n$-hexane. To consider the effect of $\varepsilon$, we evaluated the retention behaviors of halogenated benzenes in several normal alkanes (NAs), which have different $\varepsilon$. Fig. $6 b$ shows a semilogarithmic plot of the retention factors for halogenated benzenes obtained with each NA against $1 / \varepsilon^{2}$. The plot shows that $\ln k$ increased linearly with $1 / \varepsilon^{2}$. This result was consistent with the expected trend given by eqn (1) and (2) and clearly indicated that the retentions of halogenated benzenes were significantly impacted by the induced-dipole interaction.

\section{Possibility of orbital interactions influencing $X-\pi$ interactions}

Because the $\sigma$ hole behaves as an electron acceptor in halogen bonding, the contributions of the orbital interaction as well as electrostatic interaction have to be considered. Early in 1950, Mulliken showed experimental evidence of changes in the electronic structure occur upon formation of a halogen bond. ${ }^{65}$ Furthermore, many computational results have also supported the notion that orbital interactions affect halogen bonding. ${ }^{6-69}$ However, several computational studies suggested an opposing view that the orbital interaction could not largely contribute to halogen bonding. ${ }^{70-72}$ In order to promote such a complicated argument, we evaluated the contribution of orbital energy to the $\mathrm{X}-\pi$ interaction by ${ }^{1} \mathrm{H}$ NMR spectroscopy, which sensitively reflects the electronic state of protons. In our study, No-D ${ }^{1} \mathrm{H}$ NMR was employed because protic solvents can be used by subtracting the solvents peaks, briefly we utilized protic $n$ hexane as a solvent. The No-D ${ }^{1} \mathrm{H}$ NMR spectra of $o$ -
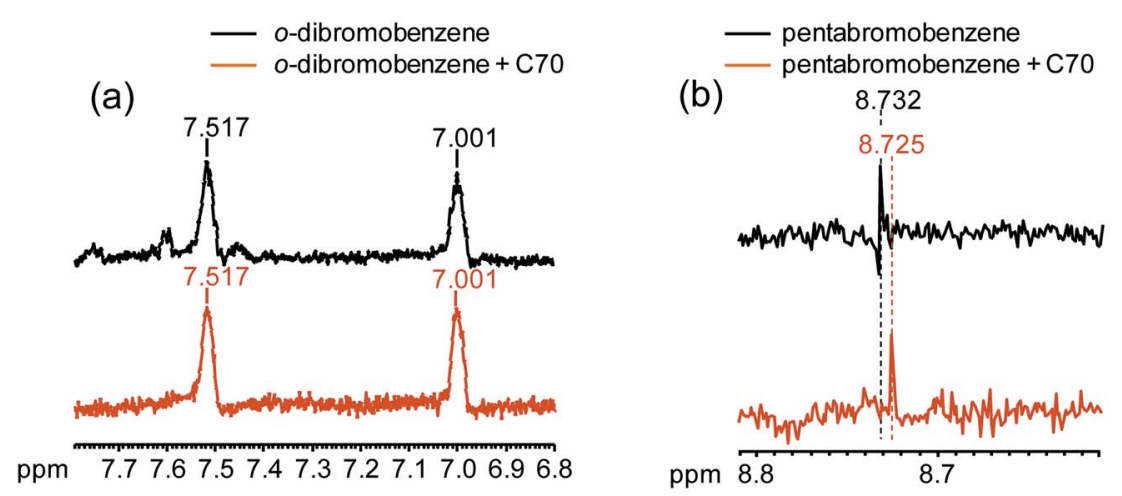

(c)

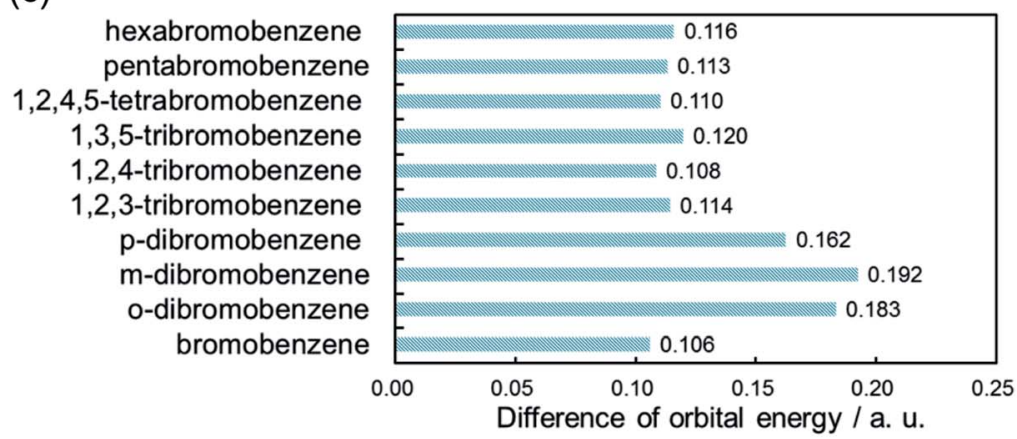

Fig. $7{ }^{1} \mathrm{H}$ NMR spectra of $\mathrm{o}$-dibromobenzene (a), pentabromobenzene (b) with/without $\mathrm{C} 70$ in $n$-hexane and the difference in orbital energy between HOMO in C70-PFPA-NHS and LUMO in each brominated benzene (c). 


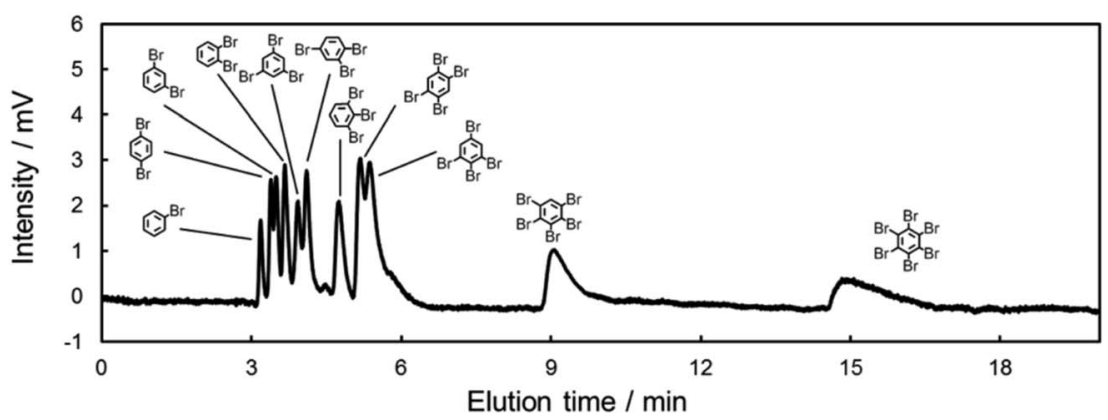

Fig. 8 Chromatogram of all isomers of brominated benzenes with the C70-coated column in NPLC. Conditions: column, C70-coated (Type-2,

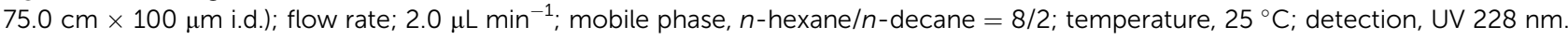

dibromobenzene and pentabromobenzene in the presence of C70 in $n$-hexane were recorded and compared with each other. Peak shifts were not observed in $o$-dibromobenzene when $o$ dibromobenzene and $\mathrm{C} 70$ were mixed (Fig. 7a). However, when pentabromobenzene was mixed with $\mathrm{C} 70$, the peak in the pentabromobenzene spectrum shifted slightly upfield (Fig. 7b). These results suggested that a proton on the pentabromobenzene was placed into a more electron rich (more shielded) environment and that pentabromobenzene, as an electron acceptor of $\mathrm{C} 70$, might be subjected to the orbital interaction. Briefly, five bromine atoms on pentabromobenzene became electron rich from the molecular interaction with $\mathrm{C} 70$; this meant that the aromatic ring and its proton were also in electron rich conditions. In addition, we carried out computer simulations to determine the differences in orbital energy between the HOMO in C70-PFPA-NHS and the LUMO in each brominated benzene (Fig. 7c). The differences in orbital energies of poly-brominated benzenes $(n>2)$ were much lower than that for dibromobenzenes and were more likely to cause orbital interactions with C70-PFPA-NHS. Furthermore, the LUMOs of poly-brominated benzenes $(n>2)$ extended in the direction of the $\sigma$ bond in the $\mathrm{C}-\mathrm{Br}$ of the bromine atoms and matched the positions showing the $\mathrm{X}-\pi$ interactions (Fig. S5 $\dagger$ ). These results also suggested that orbital interactions might contribute to the $\mathrm{X}-\pi$ interaction.

\section{One-pot separation of the entirety of brominated benzenes}

In the above discussions, we clarified the presence of $\pi-\pi$ and/ or $\mathrm{X}-\pi$ interactions between halogenated benzenes and carbon-materials. In addition, we revealed the effect of the mobile phase as being against these $\pi$ interactions. Finally, we were faced with the challenge of achieving the separation of halogenated benzenes in NPLC. This achievement will lead to efficient separations of aromatic halogens in oil. To realize this goal, we optimized the mobile phase conditions, in consideration of the dielectric effect, to achieve a one-pot separation of all isomers of brominated benzenes (11 analogues, Fig. 8). The separation of halogenated benzenes in oil samples is a major issue in the field of environmental chemistry, since many halogenated benzenes are in waste oil and are highly toxic. ${ }^{73-75}$ Therefore, the LC separation of halogenated benzenes has great importance in environmental chemistry and shows its potential for separating toxic aromatic halogens, such as polychlorinated biphenyls and polybrominated biphenyls.

\section{Conclusion}

In this study, we experimentally evaluated the strength of the X$\pi$ interaction between carbon-materials and the variety of halogenated benzenes using NPLC, in which the hydrophobic interaction was completely suppressed. Higher retentions were observed as the number of $\mathrm{Cl}, \mathrm{Br}$, or I substitutions on the benzenes increased, especially for the C70-coated column, which showed higher retention efficiencies than other carbon materials. UV absorption spectra of mono-to tri-brominated benzenes were critically changed in the presence of $\mathrm{C} 70$, indicating that these compounds mainly interacted via the $\pi-\pi$ interaction with C70. Furthermore, the number of bromine substitutions affected the strength of the $\mathrm{X}-\pi$ interaction with C70. The ${ }^{1} \mathrm{H}$ NMR spectra of $o$-dibromobenzene and pentabromobenzene in the presence of $\mathrm{C} 70$ also showed the possibility for orbital interactions based on the $\mathrm{X}-\pi$ interaction. Thus, we supposed the existence of bimodal interactions, the $\pi-\pi$ and X$\pi$ interactions, between the halogenated benzenes and aromatic materials. Using this new knowledge, we successfully demonstrated the effective separation of di- or tri-bromo benzene isomers and 11 brominated benzene analogues with a C70-coated column in NPLC by optimizing the mobile phase conditions. We believe that this report greatly contributes to elucidation of the $\mathrm{X}-\pi$ interaction and efficient separations of halogenated environmental pollutants.

\section{Conflicts of interest}

There are no conflicts to declare.

\section{Acknowledgements}

This research was supported by Environment Research and Technology Development Fund of the Environmental Restoration and Conservation Agency of Japan (5-1953) National Science Foundation CHE-1808671, and Mukai Science and Technolgy Foundation. 


\section{Notes and references}

1 M. H. Kolar and P. Hobza, Chem. Rev., 2016, 116, 5155-5187.

2 G. Cavallo, P. Metrangolo, R. Milani, T. Pilati, A. Priimagi, G. Resnati and G. Terraneo, Chem. Rev., 2016, 116, 24782601.

3 R. Wilcken, M. O. Zimmermann, A. Lange, A. C. Joerger and F. M. Boeckler, J. Med. Chem., 2013, 56, 1363-1388.

4 S. Kozuch and J. M. L. Martin, J. Chem. Theory Comput., 2013, 9, 1918-1931.

5 M. Erdelyi, Nat. Chem., 2014, 6, 762.

6 E. Danelius, H. Andersson, P. Jarvoll, K. Lood, J. Gräfenstein and M. Erdélyi, Biochemistry, 2017, 56, 3265-3272.

7 M. Erdélyi, Biochemistry, 2017, 56, 2759-2761.

8 A. Mukherjee, S. Tothadi and G. R. Desiraju, Acc. Chem. Res., 2014, 47, 2514-2524.

9 H. D. Arman, E. R. Rafferty, C. A. Bayse and W. T. Pennington, Cryst. Growth Des., 2012, 12, 4315-4323.

10 C. Ouvrard, J.-Y. Le Questel, M. Berthelot and C. Laurence, Acta Crystallogr., Sect. B: Struct. Sci., 2003, 59, 512-526.

11 H. S. El-Sheshtawy, B. S. Bassil, K. I. Assaf, U. Kortz and W. M. Nau, J. Am. Chem. Soc., 2012, 134, 19935-19941.

12 P. Metrangolo, H. Neukirch, T. Pilati and G. Resnati, Acc. Chem. Res., 2005, 38, 386-395.

13 M. J. Langton, S. W. Robinson, I. Marques, V. Félix and P. D. Beer, Nat. Chem., 2014, 6, 1039.

14 B. W. Tresca, A. C. Brueckner, M. M. Haley, P. H. Y. Cheong and D. W. Johnson, J. Am. Chem. Soc., 2017, 139, 3962-3965.

15 J. Noh, S. Jung, D. G. Koo, G. Kim, K. S. Choi, J. Park, T. J. Shin, C. Yang and J. Park, Sci. Rep., 2018, 8, 14448.

16 A. Priimagi, G. Cavallo, P. Metrangolo and G. Resnati, Acc. Chem. Res., 2013, 46, 2686-2695.

17 D. González-Rodríguez and A. P. H. J. Schenning, Chem. Mater., 2011, 23, 310-325.

18 F. Fernandez-Palacio, M. Poutanen, M. Saccone, A. Siiskonen, G. Terraneo, G. Resnati, O. Ikkala, P. Metrangolo and A. Priimagi, Chem. Mater., 2016, 28, 8314-8321.

19 H. L. Nguyen, P. N. Horton, M. B. Hursthouse, A. C. Legon and D. W. Bruce, J. Am. Chem. Soc., 2004, 126, 16-17.

20 T. A. Barendt, A. Docker, I. Marques, V. Félix and P. D. Beer, Angew. Chem., Int. Ed., 2016, 55, 11069-11076.

21 A. Vanderkooy, P. Pfefferkorn and M. S. Taylor, Macromolecules, 2017, 50, 3807-3817.

22 P. Auffinger, F. A. Hays, E. Westhof and P. S. Ho, Proc. Natl. Acad. Sci. U. S. A., 2004, 101, 16789.

23 Y. Lu, T. Shi, Y. Wang, H. Yang, X. Yan, X. Luo, H. Jiang and W. Zhu, J. Med. Chem., 2009, 52, 2854-2862.

24 L. A. Hardegger, B. Kuhn, B. Spinnler, L. Anselm, R. Ecabert, M. Stihle, B. Gsell, R. Thoma, J. Diez, J. Benz, J.-M. Plancher, G. Hartmann, D. W. Banner, W. Haap and F. Diederich, Angew. Chem., Int. Ed., 2011, 50, 314-318.

25 C. Yabe-Nishimura, Pharmacol. Rev., 1998, 50, 21.

26 D. M. Himmel, K. Das, A. D. Clark, S. H. Hughes, A. Benjahad, S. Oumouch, J. Guillemont, S. Coupa, A. Poncelet, I. Csoka, C. Meyer, K. Andries, C. H. Nguyen,
D. S. Grierson and E. Arnold, J. Med. Chem., 2005, 48, 7582-7591.

27 J. Cao, X. Yan, W. He, X. Li, Z. Li, Y. Mo, M. Liu and Y.-B. Jiang, J. Am. Chem. Soc., 2017, 139, 6605-6610.

28 C. Heroven, V. Georgi, G. K. Ganotra, P. Brennan, F. Wolfreys, R. C. Wade, A. E. Fernández-Montalván, A. Chaikuad and S. Knapp, Angew. Chem., Int. Ed., 2018, 57, 7220-7224.

29 H. Matter, M. Nazaré, S. Güssregen, D. W. Will, H. Schreuder, A. Bauer, M. Urmann, K. Ritter, M. Wagner and V. Wehner, Angew. Chem., Int. Ed., 2009, 48, 2911-2916.

30 M. B. Shah, J. Liu, Q. Zhang, C. D. Stout and J. R. Halpert, ACS Chem. Biol., 2017, 12, 1204-1210.

31 A. Voth Regier and P. Ho Shing, Curr. Top. Med. Chem., 2007, 7, 1336-1348.

32 Y. Lu, Y. Wang and W. Zhu, Phys. Chem. Chem. Phys., 2010, 12, 4543-4551.

33 S. Tsuzuki, T. Uchimaru, A. Wakisaka and T. Ono, J. Phys. Chem. A, 2016, 120, 7020-7029.

34 I. S. Youn, D. Y. Kim, W. J. Cho, J. M. L. Madridejos, H. M. Lee, M. Kołaski, J. Lee, C. Baig, S. K. Shin, M. Filatov and K. S. Kim, J. Phys. Chem. A, 2016, 120, 9305-9314.

35 F. F. Awwadi, D. Taher, S. F. Haddad and M. M. Turnbull, Cryst. Growth Des., 2014, 14, 1961-1971.

36 C. B. Aakeröy, M. Fasulo, N. Schultheiss, J. Desper and C. Moore, J. Am. Chem. Soc., 2007, 129, 13772-13773.

37 B. Zha, M. Dong, X. Miao, S. Peng, Y. Wu, K. Miao, Y. Hu and W. Deng, Nanoscale, 2017, 9, 237-250.

38 H. Sun, A. Horatscheck, V. Martos, M. Bartetzko, U. Uhrig, D. Lentz, P. Schmieder and M. Nazaré, Angew. Chem., Int. Ed., 2017, 56, 6454-6458.

39 K. Kimata, K. Hosoya, T. Araki and N. Tanaka, J. Org. Chem., 1993, 58, 282-283.

40 S. Chen and M. Meyerhoff, Anal. Chem., 1998, 70, 2523-2529.

41 T. Kubo, E. Kanao, T. Matsumoto, T. Naito, T. Sano, M. Yan and K. Otsuka, ChemistrySelect, 2016, 1, 5900-5904.

42 T. Kubo, Y. Murakami, M. Tsuzuki, H. Kobayashi, T. Naito, T. Sano, M. Yan and K. Otsuka, Chem.-Eur. J., 2015, 21, 18095-18098.

43 E. Kanao, T. Kubo, T. Naito, T. Matsumoto, T. Sano, M. Yan and K. Otsuka, Anal. Chem., 2019, 91, 2439-2446.

44 E. Kanao, T. Naito, T. Kubo and K. Otsuka, Chromatography, 2017, 38, 45-51.

45 P. Hadi, M. Xu, C. S. K. Lin, C. W. Hui and G. McKay, J. Hazard. Mater., 2015, 283, 234-243.

46 N. Quinete, A. Esser, T. Kraus and T. Schettgen, Environ. Int., 2016, 97, 171-179.

47 R. J. Law, A. Covaci, S. Harrad, D. Herzke, M. A. E. Abdallah, K. Femie, L. M. L. Toms and H. Takigami, Environ. Int., 2014, 65, 147-158.

48 E. Malliari and O. I. Kalantzi, Environ. Int., 2017, 108, 146169.

49 T. J. McGrath, A. S. Ball and B. O. Clarke, Environ. Pollut., 2017, 230, 741-757.

50 Y.-Z. Zheng, N.-N. Wang, Y. Zhou and Z.-W. Yu, Phys. Chem. Chem. Phys., 2014, 16, 6946-6956. 
51 M. A. A. Ibrahim and A. A. M. Hasb, Theor. Chem. Acc., 2018, 138, 2.

52 M. Erdélyi, Chem. Soc. Rev., 2012, 41, 3547-3557.

53 L. C. Roper, C. Präsang, A. C. Whitwood and D. W. Bruce, CrystEngComm, 2010, 12, 3382-3384.

54 M. A. A. Ibrahim, J. Comput. Chem., 2011, 32, 2564-2574.

55 R. Vijay Solomon, S. Angeline Vedha and P. Venuvanalingam, Phys. Chem. Chem. Phys., 2014, 16, 7430-7440.

56 V. A. Karachevtsev, A. M. Plokhotnichenko, M. V. Karachevtsev and V. S. Leontiev, Carbon, 2010, 48, 3682-3691.

57 T.-H. Wang, C.-S. Hsu, W.-L. Huang and Y.-H. Lo, Spectrochim. Acta, Part A, 2013, 115, 866-875.

58 J. Trnka, R. Sedlak, M. Kolář and P. Hobza, J. Phys. Chem. A, 2013, 117, 4331-4337.

59 A. Forni, S. Pieraccini, S. Rendine and M. Sironi, J. Comput. Chem., 2014, 35, 386-394.

60 S. Tsuzuki, K. Honda, T. Uchimaru, M. Mikami and K. Tanabe, J. Am. Chem. Soc., 2002, 124, 104-112.

61 C. F. R. A. C. Lima, M. A. A. Rocha, L. R. Gomes, J. N. Low, A. M. S. Silva and L. M. N. B. F. Santos, Chem.-Eur. J., 2012, 18, 8934-8943.

62 H. G. Wallnoefer, T. Fox, K. R. Liedl and C. S. Tautermann, Phys. Chem. Chem. Phys., 2010, 12, 14941-14949.

63 E. Kanao, T. Kubo, T. Naito, T. Matsumoto, T. Sano, M. Yan and K. Otsuka, J. Phys. Chem. C, 2018, 122, 15026-15032.
64 C. Präsang, A. C. Whitwood and D. W. Bruce, Cryst. Growth Des., 2009, 9, 5319-5326.

65 R. S. Mulliken, J. Am. Chem. Soc., 1950, 72, 600-608.

66 M. Palusiak, J. Mol. Struct., 2010, 945, 89-92.

67 C. Wang, D. Danovich, Y. Mo and S. Shaik, J. Chem. Theory Comput., 2014, 10, 3726-3737.

68 L. P. Wolters and F. M. Bickelhaupt, ChemistryOpen, 2012, 1, 96-105.

69 R. Desiraju Gautam, P. S. Ho, L. Kloo, C. Legon Anthony, R. Marquardt, P. Metrangolo, P. Politzer, G. Resnati and K. Rissanen, Pure Appl. Chem., 2013, 85, 1711-1713.

70 K. E. Riley and P. Hobza, J. Chem. Theory Comput., 2008, 4, 232-242.

71 S. Tsuzuki, A. Wakisaka, T. Ono and T. Sonoda, Chem.-Eur. J., 2012, 18, 951-960.

72 J. Řezáč and A. de la Lande, Phys. Chem. Chem. Phys., 2017, 19, 791-803.

73 F. M. Jaward, N. J. Farrar, T. Harner, A. J. Sweetman and K. C. Jones, Environ. Sci. Technol., 2004, 38, 34-41.

74 M. H. Jacobson, L. A. Darrow, D. B. Barr, P. P. Howards, R. H. Lyles, M. L. Terrell, A. K. Smith, K. N. Conneely, M. E. Marder and M. Marcus, Environ. Health Perspect., 2017, 125, 097020.

75 S. Safe and O. Hutzinger, Crit. Rev. Toxicol., 1984, 13, 319395. 